\title{
Improving the interpretation of fishing effort and pressures in mixed fisheries using spatial overlap metrics
}

\author{
Bourdaud Pierre ${ }^{1,{ }^{*}}$, Travers-Trolet Morgane ${ }^{2,3}$, Vermard Youen ${ }^{3}$, Marchal Paul ${ }^{4}$
}

1 Ifremer Centre Manche Mer du Nord, 121237, 150 quai Gambetta, Boulogne-sur-Mer, France,

2 IFREMER, F-62321 Boulogne-sur-Mer, cedex, France

${ }^{3}$ Ifremer Centre Atlantique, 70611, Nantes, Pays de la Loire, France

${ }^{4}$ Ifremer, Channel and North Sea Fisheries Research Unit, 150 Quai Gambetta, Boulogne sur mer, France,

* Corresponding author : Pierre Bourdaud, email address : pierre.bourdaud@ifremer.fr

\begin{abstract}
:
Managing mixed fisheries requires understanding fishers' behaviour to allow predicting future fisheries distribution and impact on marine ecosystems. A new approach was developed to compare fine scale fishing effort distribution of Eastern English Channel (EEC) bottom trawlers, to the monthly- and spatially-resolved abundance distributions of commercial species. First, the added-value of using species-specific spatial overlap metric to quantify effective fishing effort and improve the relationship between fishing effort and fishing mortality was assessed. Second, based on the Ideal Free Distribution (IFD) theory, the species-specific weights given by fishers to different species were estimated by maximizing the overlap between target species assemblage and effort distributions in October. At a seasonal scale our results emphasized the importance of cuttlefish and red mullet for the global distribution of EEC bottom trawlers. In October, cuttlefish and red mullet were clearly more determining fishers' location choice than historically harvested species, and also than the overall expected revenue. This is likely due to external constraints such as low cod quota, causing IFD assumptions violated. This study evidenced the importance of getting good insights into spatio-temporal distributions of stocks and fleets to understand fishers' behaviour and improve mixed fisheries management advice
\end{abstract}

Keywords : fishing effort, seasonality, target species assemblages, Eastern English Channel 


\section{Introduction}

33 The implementation of Ecosystem-Based Fisheries Management (EBFM) entails new methods

51 fishing patterns are changing.

52 With regards (i), a number of fishing effort analyses have focused on the identification of

53 manageable fishing units (Laurec et al. 1991; Marchal 2008; Ulrich et al. 2012). Other fishing

54 effort studies have focused on the quantification of fishing power and/or of the relationship

55 between fishing effort and fishing mortality, with a focus on technical development (Kirkley et 
al. 2004; Marchal et al. 2007; Eigaard et al. 2014) and tactical adaptations (Hilborn 1985; Rose and Kulka 1999; Salthaug and Aanes 2003). The metrics considered in these studies were used to standardise nominal fishing effort and calculate an effective fishing effort, thereby improving the estimation of the actual fishing pressure exerted on fish stocks. Such metrics, however, were derived from vessels, gears and/or skippers' characteristics only, and hence not explicitly considering the relative availability of the different targeted species. In our study, we calculate effective fishing effort including fish availability and fishers' ability to target and catch fish, which we quantify by the overlap between stocks and fishers' spatial distributions.

The first objective of this study will then be to quantify the effective fishing effort in a mixed fishery's context, and in fine improve the relationship between fishing effort and fishing mortality (Gascuel et al. 1993; Winker et al. 2013; García-Carreras et al. 2015), using a combination of vessel characteristics and species-specific spatial overlap metrics.

With regards (ii), fleet dynamics has been subject to considerable attention in the past decades (see Van Putten et al. 2012 for a review), a process largely supported by fine-scale and georeferenced data becoming increasingly available (e.g., Bastardie et al. 2010; Hintzen et al. 2012). Different theories have been proposed to explain the mechanisms of fishers' behaviour. The Ideal Free Distribution (IFD, Fretwell and Lucas 1970; Fretwell 1972) is one of the most widespread conceptual approaches that has been applied to predict the distribution of foragers (here fishers) in relation to available resources (Kacelnik et al. 1992; Kennedy and Grey 1993). The IFD states in particular that the number of foragers that will aggregate in various areas is proportional to the amount of resources these may supply. In a fisheries context, the spatial distribution of nominal fishing effort and of their harvested resource would then overlap (Abrahams and Healey 1993; Gillis et al. 1993; Rijnsdorp et al. 2000). In mixed fisheries, where several fish species are harvested together, the amount of resources has often been translated 
80 into aggregated economic revenue metric like the value per unit of effort (VPUE) (e.g.

81 Rijnsdorp et al. 2000; Abernethy et al. 2007; Gillis and van der Lee 2012), making the

82 hypothesis that fishers would try to maximize their expected revenue more than the volume of 83 species they could catch.

84 Applying the IFD results in fishers' behaviour being fully driven by short-term economic 85 consideration: the species with the largest expected return is the most targeted.

86 However, many studies have shown that species targeting could also be driven by other factors

87 including regulations as well as longer-term economic and social considerations. For instance,

88 valuable species may be avoided, when fishers do not have a sufficient quota provision to

89 harvest them (e.g., choke species; Schrope 2010; Ulrich et al. 2011; Baudron and Fernandes

90 2014), or because they do not have a market channel to sell them (Marchal et al. 2009), or

91 because targeting these species is not part of their habit (Vermard et al. 2008; Marchal et al.

92 2009; Girardin et al. 2017), thereby inducing deviations from the basic IFD predictions. These

93 results suggested in particular that the relative interest fishers give to the different species they

94 harvest is not entirely reflected by their landed value.

95 The second objective of this study is then to quantify, using a novel method, the relative value

96 fishers assign to their different targets, and to link it with current knowledge of their ecological,

97 economic and regulatory environment.

98 The research pertaining the two objectives of this study will be evaluated for a typical EU mixed

99 fishery, consisting of French otter trawlers harvesting demersal species in the Eastern English 100 Channel.

101

102

\section{Material and methods}

103

\subsection{Study area and fleet characteristics}


104 The Eastern English Channel (EEC; ICES Division 27.7.d) is delineated by latitudes $49.3^{\circ} \mathrm{N}$ and $10551^{\circ} \mathrm{N}$ and longitudes $2^{\circ} \mathrm{W}$ and $2^{\circ} \mathrm{E}$ (Figure 1 ). This shallow area constitutes a corridor between 106 the northeast Atlantic Ocean and the North Sea, and is home to intense and diversified human 107 activities including fishing, shipping, wind farms, aggregate extraction (Ulrich et al. 2002; 108 Dauvin 2012). This area is also important for several commercially important migratory species, 109 e.g., red mullet (Mullus surmuletus) (Mahé et al. 2005), mackerel (Scomber scombrus) (Eltink et 110 111 112 targeting a reduced list of species (EC 1998). al. 1986), herring (Clupea harengus) (ICES 2015), European seabass (Dicentrarchus labrax) (Pawson et al. 2007) and cuttlefish (Sepia officinalis) (Boucaud-Camou and Boismery 1991). The current study focuses on French exclusive (i.e. using the same gear throughout the year) bottom otter trawlers (OTB), of length above $18 \mathrm{~m}$ and using a mesh size above $80 \mathrm{~mm}$. This fleet category is an archetype of mixed fisheries and is studied here for three reasons. First, this fleet category gets the bulk of yearly French bottom otter trawlers catches for the main demersal species in the EEC (Table S1). Second, as non-exclusive OTB are usually smaller than exclusive ones, they mostly operate in coastal areas close to their home harbor thus their spatial distribution is limited and only covers a limited portion of the EEC. Finally, exclusive otter trawlers above $18 \mathrm{~m}$ generally use the same gear (with a mesh size above $80 \mathrm{~mm}$ ) all year round, making the exploration of their dynamics more tractable. Mesh sizes below $80 \mathrm{~mm}$ are rarely used by this fleet (for only 5\% of their landings in average, see Table S1), and only when

\subsection{Data}

125 This study requires spatial distributions of otter trawlers' nominal fishing effort and of the 126 abundance of the main EEC stocks they harvest in terms of tonnage and revenue (Table 1). To 127 estimate species distribution, both in time and space, we used the delta-GLM (Generalized 
128 Linear Model) approach described by Bourdaud et al. (2017) that is applied separately to survey 129 and commercial data.

130 The input data sources for this delta-GLM are the Channel Ground Fish Survey (CGFS) for the 131 fisheries independent data and on-board commercial fisheries observation (hereby named as 132 OBSMER) data for the fisheries dependent information. These data sources are complementary, 133 with CGFS data providing insights into inter-annual patterns (only in October, when the survey 134 is operated), and OBSMER data being fit to investigate seasonal variability. Spatial distribution 135 of species abundances are computed for each species above a length threshold ( $\mathrm{L}_{\mathrm{s}}$; Ravard et al. 136 2014), where individuals are considered to be well sampled. For species with a minimum 137 landing size (MLS) in the EEC, $\mathrm{L}_{\mathrm{s}}$ was assigned to that MLS. For others, $\mathrm{L}_{\mathrm{s}}$ was approximately 138 set for each species at the length of the highest mode of the length-frequency of combined 139 catches from the different gears (Table 1). The delta-GLM applied to OBSMER data contains a 140 maximum of six explanatory variables:

$\operatorname{logit}\left(\mathrm{p}_{\mathrm{v}, \mathrm{i}, \mathrm{m}, \mathrm{y}}^{>0}\right)=\beta_{i} \delta_{m}+\lambda_{y}+\omega_{g} l+\vartheta_{s}$

$\log \left(I A_{v, i, m, y}^{>0}\right)=\beta_{i} \delta_{m}+\lambda_{y}+\omega_{g} l+\vartheta_{s}+\varepsilon_{v, i, m, y}$

143 where $p_{v, i, m, y}^{>0}$ is the mean presence probability and $I A_{v, i, m, y}^{>0}$ the CPUE of a species caught by 144 vessel $v$ of length $l$ rigged with gear $g$ (e.g. bottom otter trawl, trammel net), fishing in $\left(0.3^{\circ} \mathrm{x}\right.$ $1450.3^{\circ}$ ) area $i$, year $y$ and month $m . \beta_{i}$ is the area effect of the fishing operation (treated as factor), $146 \delta_{m}$ is the month effect of the fishing operation, $\lambda_{y}$ is the annual effect, $\omega_{g}$ is the gear effect, $\vartheta_{s}$ is a 147 sediment effect, which accounts for small scale habitat variability and is decomposed into five 148 categories $s$ : mud, fine sand, coarse sand, gravel and pebble, based on a sediment map of EEC 149 from Larsonneur et al. (1982), and $\varepsilon_{v, i, m, y}$ a term of residual error. 
150 Sediments proved to have the strongest influence on the distribution of species in the shallow

151 EEC, compared to, e.g., depth, temperature and salinity (see Carpentier et al. 2009). For

152 complete justifications about the choices of the models parameterization, see Bourdaud et al. 153 (2017).

154 The final predicted abundance values $I A_{v, i, m, y}$ from commercial data are obtained by the product 155 of presence probabilities $p_{v, i, m, y}^{>0}$ and CPUE for positive values $I A_{v, i, m, y}^{>0}$.

156 CGFS survey data are always collected in October (i.e. no month effect) with the same research 157 vessel (i.e. no vessel or gear effects), hence the previous formula was reduced to the following, 158 with a maximum of three explanatory variables:

$159 \operatorname{logit}\left(\mathrm{p}_{\mathrm{i}, \mathrm{y}}^{>0}\right)=\beta_{i}+\lambda_{y}+\vartheta_{s}$

$\log \left(I A_{i, y}^{>0}\right)=\beta_{i}+\lambda_{y}+\vartheta_{s}+\varepsilon_{i, y}$

161 The final predicted abundance values $I A_{i, y}$ from survey data are obtained by the product of 162 presence probabilities $p_{i, y}^{>0}$ and CPUE for positive values $I A_{i, y}^{>0}$.

163 In the delta-GLM applied to commercial CPUEs, every parameters were kept, except the 164 sediment parameter in the presence/absence model of cuttlefish (Table S2). In the delta-GLM 165 applied to survey CPUEs, the parameters selection was case-dependent (Table S3).

166 Access to all fishing effort information was provided by the French Directorate for Sea Fisheries 167 and Aquaculture (DPMA). Nominal fishing effort is derived from the Vessel Monitoring System 168 (VMS) and is here defined as an amount of fishing time for each month in a $0.3^{\circ} \times 0.3^{\circ}$ area, a 169 scale chosen to match the scale of the species abundance distributions computed above, and 170 corresponding to a trade-off between the amount of data required and a sufficient level of 171 precision (Bourdaud et al. 2017). 
172 To validate our results, we used monthly landings derived from combined logbooks and sales 173 slips record (SACROIS) over the period 2008-2014. Landings data extracted from SACROIS 174 were available by vessel, fishing trip, ICES rectangle and gear used. Activity calendars, 175 collected directly from fishers on a regular basis by Ifremer, provided fishers' targeting 176 intention, i.e. species assemblage targeted during each fishing operation. These assemblages 177 were chosen to be the closest to the studied species (Table 1). For French exclusive OTB 178 operating in the EEC during the period $2008-2014,70 \%$ of the target assemblages in the 179 calendars were classified as 'fishes (miscellaneous)', indicating no specific target. Among the 180 remaining records, $79 \%$ mentioned targets corresponding to one of the species studied here. 181 Numbers of fishing days are summed by month for each target species and were scaled to the 182 year in order to obtain a monthly relative distribution of fishing time targeting this species.

\subsection{From nominal fishing effort to spatially-derived species-specific fishing pressure}

As defined by Mahévas et al. (2004) and Bordalo-Machado (2006), the effective fishing effort

$(f e)$ measures the real pressure exerted by fishers on a stock during a time unit. It can be defined as the product of the nominal fishing effort $(f n)$ and a global fishing power, i.e., the ability of a fisher to catch available fish. The global fishing power combines the capacity of fishers to find the targeted fish (targeting capacity), and the catching capacity inferred from vessels' physical attributes, e.g., vessel length (physical capacity).

191 Physical capacity $P_{c}$ is assumed to correspond to the $\omega_{g} l$ term for OTB gear in the delta-GLM 192 equations 1 and 2 applied to commercial data, and characterizes the impact of vessel length and 193 the gear effect on fish catchability. This parameter is used to weight nominal fishing effort per 194 spatial unit by the length category of each vessel: 
$195 I f_{k, i, m, y}=\sum_{v} f n_{v, i, m, y} \times P c_{l, k}$

196 Where $I f_{k, i, m, y}$ is the integrated nominal fishing effort in area $i$ for species $k$ fished by a vessel $v$ of 197 length $l$ during the month $m$ and year $y$.

198 Targeting capacity is then measured for each species $k$ as the similarity between the distributions 199 of integrated nominal fishing effort and of harvested fish, using the spatial overlap index LIC 200 (Local Index of Collocation, Woillez et al. 2009):

201

$L I C_{m, y}=\frac{\sum_{i} I f_{i, m, y} \times I A_{i, m, y}}{\sqrt{\sum_{i} I f_{i, m, y}{ }^{2} \times \sum_{i} I A_{i, m, y}}}$

202 Noting $I A_{i, m, y}$ the abundance of the species concerned in area $i$ during month $m$ of year $y$, 203 estimated from on-board commercial data. The LIC was computed using R package $204\{$ RGeostats $\}$ (Renard et al. 2014),

205 it ranges between 0 , showing absolutely no match between the two spatial distributions, and 1 , 206 demonstrating a perfect match between them.

207 Finally the monthly relative fishing effort of each year (i.e. between 0 and 1 , with the sum of 208 fishing effort in each year $=1$, see Figure 2 ) is weighted by the monthly LIC:

$209 f e_{m, y}=\frac{L I C_{m, y} \times \sum_{v} \sum_{i} f n_{v, i, m, y}}{\sum_{m}\left(L I C_{m, y} \times \sum_{v} \sum_{i} f n_{v, i, m, y}\right)}$

210 In order to evaluate the respective merits of $f e$ and $f n$, in reflecting actual fishing pressure, both 211 effort values were compared with available surrogates of fishing pressure: 2008-2014 averaged 212 monthly landings (as extracted from SACROIS) and fishers' intentions (expressed for each 213 month as the number of days targeting a given species, as extracted from activity calendars). 214 We computed the residual sum of squares (RSSQ) between the monthly resolved time series of, 215 (1) nominal fishing effort ( $f n$ ) and landings, (2) effective fishing effort (fe) and landings, (3) 216 nominal fishing effort and fishers' intention and, (4) effective fishing effort and fishers' 
217 intention. Should the effective fishing effort we processed in this study reflect actual fishing

218 pressure better than nominal fishing effort, we could then expect that $f e$ would track monthly

219 variations of both landings and fishers' intentions more closely than $f n$, for those species being

220 targeted by otter trawlers. This improvement would also result in the RSSQ derived from (2)

221 (respectively (4)) being lower than the RSSQ derived from (1) (respectively (3)).

222

223

\subsection{Defining species targeting factors for mixed fisheries from spatial overlap metrics}

224 While the monthly species-specific effective effort computed previously aims at better 225 apprehending the variations of the fishing pressure exerted on each single species, it does not 226 allow evaluating how variable the effort allocated to each species targeting is relative to the 227 others. A combined-species approach is thus required to get better insights into the full 228 dynamics of species targeting in a mixed fisheries context, including swaps from one target to 229 another and their determinism. Combined-species targets were computed building on the 230 maximization of the spatial overlap, measured with the LIC metric, between the distributions of 231 fishing effort and of weighted combined-species abundances. Such approach requires a 232 comprehensive and consistent spatial coverage across all species being considered, and therefore 233 could only be realized for October, the only month covered by a scientific survey over the entire 234 EEC, limiting the results to reflect inter-annual variations with no exploration of seasonal 235 patterns. In order to maximize the LIC, each of the $(\mathrm{k})$ species relative spatial distributions (i.e. 236 scaled between 0 and 1) is multiplied by a combined-species targeting coefficient, $\beta$, which is 237 bounded between 0 and 1 using the transformation:

$238 \quad \beta_{k}=\frac{e^{\alpha_{k}}}{\sum_{k} e^{\alpha_{k}}}$ 
239 Where $\alpha$ is the unconstrained coefficient to be optimized, using the 'optim' function of the R 240 package \{stats\} (R Core Team 2013) and the L-BFGS-B method. Using relative spatial 241 distributions allows to combine the different species even if their catchabilities vary. The 242 objective function to be maximized with respect to $\alpha$ may then be formulated as:

$$
\frac{\sum_{i}\left[f e_{i} \times \sum_{k}\left[\left(\frac{e^{\alpha} k}{\sum_{k} e^{\alpha_{k}}}\right) \times\left(\frac{I A_{k, i}}{\sum_{i} I A_{k, i}}\right)\right]\right]}{\sqrt{\sum_{i} f e_{i}{ }^{2} \times \sum_{i}\left[\sum_{k}\left[\left(\frac{e^{\alpha_{k}}}{\sum_{k} e^{\alpha_{k}}}\right) \times\left(\frac{I A_{k, i}}{\sum_{i} I A_{k, i}}\right)\right]^{2}\right]}}
$$

244 If fishers' foraging pattern was in consistency with IFD predictions, one could assume that 245 fishing effort distribution would match EEC wealth distribution. The amount of available 246 revenue $W$ generated by each area $i$ in year $y$ may be computed by:

$W_{i, y}=\sum_{k}\left(I_{k, i, y} \times\right.$ Price $\left._{k, y}\right)$

248 knowing the abundance of species $k$ in the area obtained from CGFS data and the mean price of

249 the species in October in year $y$ (Table S4). We consider here that differences in the catchability 250 between the main species caught during the survey and the commercial trawls would be in the 251 same order of magnitude, so equation 10 may be used to infer and compare the fishers' revenues 252 operating in an area relative to the other.

253 The LIC values obtained from maximizing (9) are then compared to the LIC obtained from the 254 comparison between fishing effort and available wealth in the EEC, one of the main hypothesis 255 of fishing location driver (van Putten et al. 2012).

\section{3. Results}

258 3.1. Seasonal fishing pressure exerted on each commercial species

259 The seasonal variation of effective fishing effort is shown for each species separately in Figure 
261 seabass have the most pronounced pattern, with peaks reached in autumn for the former, and 262 spring and autumn for the latter. Fishing pressure exerted on other species (see for example 263 plaice or squids) exhibited a smoother seasonal pattern, with a peak in winter. Fishing pressure 264 and landing seasonal patterns match for some species (cod, cuttlefish, plaice, red mullet, squids), 265 but not for others (mackerel, seabass, whiting).

266 Fishers' intention from activity calendars were strongly related to the landings, except for cod, 267 red mullet, plaice and black seabream, but were subject to wider inter-annual fluctuations 268 (Figure 3). There is a good match between fishing pressure and fishers' intention for cuttlefish 269 and seabass except in autumn, but not for the other species under consideration.

270 Considering monthly $f e$ instead of $f n$ improves substantially the correlation between fishing 271 effort and landings for two species: red mullet and cuttlefish (Figure 4A). At the same time, 272 substituting nominal by effective effort does not improve the correlation between effort and 273 landings, and even deters it for mackerel, whiting, and seabass. Almost similar average results 274 are obtained when investigating the effects of substituting nominal by effective fishing effort on 275 the correlation with the species-targeted numbers of fishing days derived from activity 276 calendars, but these were subject to large inter-annual fluctuations (Figure 4B).

278 3.2. Combined-species targeting

279 The relative target factors obtained by maximizing the ( $\beta$-weighted) LIC are presented in Figure 2805 for the six main October commercial species: cod, cuttlefish, mackerel, red mullet, squids and 281 whiting. In October, the two main target species of French exclusive OTB are cuttlefish (44\% of 282 the annually averaged sum of target, with a peak of $78 \%$ in 2012$)$, and secondly red mullet $(22 \%$ 283 on average, peaking to $59 \%$ in 2009 ). It is worth noting that the inter-annual variability can be 284 very high for these species. For instance, the targeting factor for cuttlefish goes from $0 \%$ in 2009 
285 to $78 \%$ in 2012 , while the red mullet factor goes from $0 \%$ in 2012 to $59 \%$ in 2009 . The targeting 286 factors of mackerel, cod and squids are less variable over the years, and fluctuate between $0 \%$ 287 and 29\%. Finally, whiting never appears to be targeted.

288 The maximized ( $\beta$-weighted) LIC value was compared with the revenue-based LIC value, i.e., 289 reflecting the overlap between fishers' distribution and the potential revenue W (Table 2). Every 290 year the LIC value obtained by maximization was higher than the revenue-based LIC by at least 2910.10 , even reaching 0.22 in 2014. The range of maximized LIC is of 0.57-0.81, while the range 292 of revenue-based LIC values is of 0.46-0.63, almost always below the 0.60 threshold below 293 which spatial overlap is not meaningful (Scrimgeour and Winterbourn 1987). This represents a 294 substantial deviation from the IFD predictions.

295

\subsection{Species targeting fluctuations and external factors}

297 Cuttlefish abundance and economic attractiveness is highly fluctuating during the period, with 298 peaks in 2010 and 2012 (Figure 6A). Cuttlefish targeting intensity follows economic 299 attractiveness well, except for 2009 where there is no targeting. The correlation is particularly 300 visible in the 2010-2014 fluctuations. Cod abundance and economic attractiveness show a clear 301 decrease from 2008 to 2010, and then remain constant, while remaining quota shows at the same 302 time an increase before being constant (Figure 6B). Cod targeting intensity increases from 6 to $30315 \%$ between 2008 and 2010, when abundance and economic attractiveness both decrease. From 3042010 onwards, the cod targeting factor is consistently above $10 \%$, except in 2012 . No clear 305 pattern in abundance, attractiveness or remaining quota can be related to the low 2012 targeting. 306 However, it may be noted that during 2012 the targeted species were dominated by cuttlefish 307 (see Figure 5). 


\section{4. Discussion}

\section{4.1. An improved quantification of fishing pressure}

311 Adjusting nominal fishing effort using the species-specific LIC improved our understanding of 312 seasonal fishing pressure (here measured by relative landings and species targeting expressed by 313 fishers) exerted by French otter trawlers on EEC cuttlefish and red mullet. These results have 314 direct operational implications, as such effective fishing effort could be used to remove the 315 seasonal effect in catch rates series used to calibrate cuttlefish and red mullet stock assessments. 316 Such an improvement in the relationship between seasonal fishing pressure and fishing effort 317 could not be observed for the other species under investigation, and particularly cod and 318 whiting, which used to be traditional target species for French otter trawlers. Several reasons 319 could explain a lack of improvement (or even a deterioration) in the relationship between fishing 320 effort and estimated fishing pressure: i) high discards rate, which is not accounted for in 321 landings data, ii) high spatial patchiness for some species, which increases landings variability, 322 iii) high monthly fluctuation in biomass, which is not taken into account in landings data (e.g. 323 migration from or to the EEC) and finally, iv) limited spatial coverage of abundance indices 324 derived from fisheries-dependent OBSMER data (Bourdaud et al. 2017).

325 In their study, Sagarese et al. (2015) also quantified the overlap between fish distribution from 326 survey data and fishing effort, in order to quantify the availability of spiny dogfish to sink 327 gillnetters and otter trawlers. However, their approach was designed in a binary fashion (i.e. 328 presence/absence), compared to ours, as they compared the number of cells with fishing effort 329 and the number of cells with presence of spiny dogfish Squalus acanthias. Note that we assumed 330 here a linear relationship between fishing pressure and our LIC spatial overlap index. Such a 331 linear relationship is, however, a first proxy, and more work could be dedicated to finding either 
332 refined spatial overlap indices, or more realistic relationships relating the LIC to the real fishing 333 pressure exerted on the different fish species.

334 Previous studies have been able to quantify other impacting factors on catchability, such as 335 technical effects (Rijnsdorp et al. 2006; Marchal et al. 2007; Mahévas et al. 2011), individual 336 vessel effects (Tidd 2013; Thorson and Ward 2014) or vessel competition (Gillis and van der 337 Lee 2012). The effects of technological creep could in principal enhance the perception of 338 fishing pressure we obtained. In our case study, technological differences among vessels and 339 among years are, however, expected to be relatively limited, as we only focus on one single fleet 340 category, the French OTB $>=18 \mathrm{~m}$, and on a relatively short period of time (seven years).

\subsection{Fishers' intentions and the IFD}

343 The IFD theory builds on several key assumptions: i) interference competition among vessels 344 exists in proportion to their local density, ii) fishers have equal competitive abilities, iii) no 345 restrictions exist for effort allocation and iv) ideal knowledge of fishing grounds' local density 346 (Gillis 2003). We consider in this study that a poor spatial overlap between the distributions of 347 fishing effort and of available wealth results from one or several of IFD assumptions being at 348 fault. Deviations from IFD predictions are then related to factors that could potentially 349 compromise the validity of these base assumptions. In doing so, we particularly considered 350 assumption (iii), since additionally to external economic factors such as fuel costs (Poos et al. $3512010 ; 2013)$ or spatial competition, fishing access to several of the EEC species being 352 investigated (and hence effort allocation) has been restricted by Total Allowable Catches, direct 353 effort (number of days at sea) limits, and minimum mesh size regulations. This is particularly 354 true for cod, for which a recovery plan has been implemented since 2002 in the North Sea and 355 the EEC. Departs from assumptions (ii) and (iv) are considered more limited, since we consider 
356 vessels belonging to one fleet category and no individual quotas are presently set for these boats

357 (ii), and because the EEC is a small and shallow maritime domain, so we can reasonably assume 358 that fishers have a good knowledge of their fishing grounds (iv). Although the legitimacy of 359 assumption (i) is difficult to evaluate, previous studies did evidence that interference 360 competition occurs between EEC fishing fleets (Girardin et al. 2015; Tidd et al. 2015).

361 Mixed fisheries in the Eastern English Channel target an assemblage of different species 362 (Marchal 2008, Girardin et al. 2015, ICES 2017), and our study proposed a novel approach, 363 building on the optimization of a spatial species abundance / fishing effort overlap metric, to 364 identify their key targets, and hence fishers' intentions. This approach was applied only in 365 October as it required a good spatial coverage of both fishing effort and species distributions. 366 Although Quirijns et al. (2008) also determined an explicit index for the targeting behaviour in a 367 mixed fisheries context involving two species (i.e. sole and plaice in the North Sea), our 368 approach is different as it explores fishers' intentions using fishery-independent data, and in an 369 optimization fashion.

370 Our results evidenced that cuttlefish and red mullet have been the primary target species of the 371 French EEC bottom trawlers over the period 2008-2014, which confirmed the strong fishing 372 pressure exerted on both species in October (Figures 2 and 3). It is informative that cuttlefish 373 and red mullet, the catch of which is not limited by quotas, are much more targeted than cod, 374 whiting and mackerel, three species managed by TAC (Total Allowable Catches). This could 375 result from an adaptation of fishers to increasingly restrictive TAC limitations, and more 376 particularly in the context of the North Sea recovery plan (Horwood et al. 2006), thereby 377 confirming the decline of traditional targets and the emergence of valuable and poorly regulated 378 species such as red mullet (Mahé et al. 2005) and cuttlefish (Gras et al. 2014). Concerning 
379 cuttlefish this can also be an adaptation to a gain in economic attractiveness during the same 380 period (Figure S1).

381 It is noteworthy that mackerel has a significant target factor value every year in October. This 382 could be seen as a surprise, as pelagic species such as mackerel are not usually targeted by 383 bottom trawlers. This could be due to the nature of the EEC, a shallow sea $(<50 \mathrm{~m})$, with strong 384 mixing and benthic-pelagic coupling processes (Giraldo et al. 2017). The substantial mackerel 385 targeting contrasts, however, with the weak (and even negative) effect of the LIC on the 386 computed fishing pressure exerted on this species. This contrast may be explained by the larger 387 intra- and inter-annual abundance fluctuations pelagic species are subject to, compared to the 388 other species we considered.

389 The optimized spatial overlap between the distributions of fishing effort and the combined390 species resource was achieved with species-specific weightings differing substantially from the 391 available revenue coefficients used to derive VPUE as the aggregated resource metric. This 392 difference measures the deviation between the actual spatial distribution of fishing effort and the 393 one predicted under the IFD. In previous studies, the IFD provided a useful conceptual 394 framework to predict fishing effort distribution patterns (e.g. Gillis and Frank 2001; Swain and 395 Wade 2003). In several studies, however, the IFD did not predict fishing effort distribution well, 396 which was interpreted as limited knowledge of fishing grounds, or external foraging constraints 397 (Pet-Soede et al. 2001; Abernethy et al. 2007).

398 In our study, and without excluding other possible causes, we interpret here the deviation 399 between observed and predicted effort patterns as IFD assumption (iii) (unrestricted access to 400 the different EEC fishing grounds) being at fault and this for several reasons. First, while the 401 large trawlers investigated here have the capacity to cover all the EEC, they might limit their 402 visits to the closest fishing grounds to save fuel and time at sea costs. Second, weather and 
403 especially wind conditions could be poor in the EEC, and could influence the choice of fishing 404 grounds (Wilen et al. 2002; Respondek et al. 2014). Third, fishing habits may be more 405 influential than economic opportunism in choosing fishing grounds (Salas and Gaertner 2004; 406 Holland 2008; Girardin et al. 2017), although these may be highly correlated (Van Putten et al. 407 2012). Fourth, the EEC is a particularly congested sea, where fisheries may compete for space 408 with other fisheries, or other maritime activities (e.g., shipping, aggregate extractions), which 409 could occasionally restrict their activities (Girardin et al. 2015; Tidd et al. 2015).

410 Finally, management is an obvious cause of restricted access to fishing grounds. This has been 411 evidenced extensively in the case of Marine Protected Areas (e.g. Stelzenmüller et al. 2008;

412 Dowling et al. 2012), although the fleet investigated in our study is only subject to limited 413 spatial management measures within the 12 nautical miles coastal areas (EC 1998). TAC 414 management may also affect the spatial distribution of fishing effort (Batsleer et al. 2013; 415 Baudron and Fernandes 2014), particularly when the TAC for a species is so low that this 416 species becomes a choke species. This is an issue that we have investigated more thoroughly 417 here, as cod has become a choke species in the EEC following the 2002 implementation of the 418 North Sea cod recovery plan (Horwood et al. 2006), with an impact on the spatial distribution of 419 EEC bottom trawlers and their cod targeting.

\subsection{Influence of external factors on species targeting fluctuations}

422 The interpretation of cod targeting fluctuations is not straightforward. Thus, it seems at first 423 glance difficult to capture why cod targeting increases over 2008-2010, while stock abundance 424 reflected by CGFS decreases during the same time period. The rationale underlying these 425 contrasted trends becomes, however, clearer when one considers the drastic increase in the 426 unutilized cod quota, from 0 tons in 2008 to 817 tons available in October 2010. With cod quota 
427 becoming somehow less restrictive, it is not surprising that cod targeting increased somewhat.

428 The 2011-2014 fluctuations in cod targeting, and the drop observed in 2012, are difficult to 429 explain without considering the other species' targeting factors. Thus cuttlefish targeting, not 430 restricted by quotas, varied synchronously with economic attractiveness, over 2008-2014, with a 4312012 maximum corresponding to the sharp decrease in cod targeting concomitantly with a high 432 economic attractiveness for cuttlefish during that year. Another illustration of the combined433 species targeting complexity is the decline of red mullet targeting between 2008-2009 and 2010434 2014. This could be due to increased spatial and market competition with Dutch fly-shooters, 435 which targeted red mullet in the EEC from 2010 onwards (Marchal et al. 2014). The low red 436 mullet targeting observed in 2012-2013 could also be related to the low abundance and 437 economic attractiveness for this species during that year (Figure S2).

438 Future work could be dedicated to identifying groups of fishers according to their targeting 439 patterns, leading to a more precise definition of métiers, and also to evaluate whether habits 440 could be detected in these patterns. We also made a number of simplifications, which could be 441 revisited. Thus, we neglected fishers' home harbour, although this has implications on travel 442 costs, fishing grounds location, and hence the validity of IFD-based effort predictions (Gordon 443 1953; see also Gillis 2003 for a review). Furthermore, in combination with spatio-temporal 444 distributions of species abundance and fish prices fluctuations, geographical features can induce 445 traditional fishing patterns only revealed by fishers' interviews (Christensen and Raakjær 2006; 446 Boonstra and Hentati-Sundberg 2014).

447 The method developed in this study is not aimed at forecasting fishers' intentions, as past 448 choices are not causal (Van Putten et al. 2013). However, it could be included in individual449 based models (IBM), which are considered particularly well-adapted for forecasting, especially 450 in changing management regimes (Ulrich et al. 2012; Van Putten et al. 2012). Our approach 
451 could thus be combined to a number of existing integrated ecological-economic fisheries models 452 (see Nielsen et al. 2017 for a review), by supplying knowledge on real fishers' intentions, which 453 may contrast with preliminary modelling assumptions and choices.

454 A future development of this study could also be to consider extensions from the IFD conceptual 455 framework, such as isodars (for 'iso-Darwin'; Morris 1988, 2003). Isodars build on an 456 ecological theory, predicting numbers in one area knowing numbers in another area and explicit 457 expressions of local density-dependent per capita fitness. Isodars have been applied to fleet 458 dynamics by Gillis and van der Lee (2012) and even proved to predict observations better than 459 discrete choice models (van der Lee et al. 2014). If determination of the nature of factors in 460 isodars may not be easily interpretable, a challenge could be to develop the approach at a more 461 disaggregated level (e.g. by home port) so to, (i) gain better knowledge of the basic desirability 462 level of the different fishing areas at fine scale, in relation to associated operational costs and 463 tradition aspects and, (ii) improve the estimation of species target factors, by including those 464 area desirability factors identified in (i).

465 This study used spatial distributions collocations to improve the definition of fishing effort and 466 our understanding of its determinism. Our results at seasonal scale emphasized the importance 467 of cuttlefish and red mullet in determining the global distribution of Eastern English Channel 468 bottom trawlers. These results have clear management benefits, in improving the definition of 469 catchability, effective fishing effort, and how these relate to fishing mortality for red mullet and 470 cuttlefish. We also used a metric measuring the optimized spatial overlap between fishing effort 471 and combined-species abundances. It revealed the importance of cuttlefish, red mullet and, to 472 some extent, mackerel targeting relative to the other species in October, which was in contrast 473 with IFD predictions, probably owing to external factors including limiting quota, travelling 
474 costs, or competition with other sectors of activity. Our results could be validated by available 475 fishers' knowledge (e.g. Neis et al. 1999; McCluskey and Lewison 2008; Hind 2015).

476 


\section{Acknowledgments}

478 This study was partly funded by the European Union's Horizon 2020 research and innovation 479 programme under Grant Agreement No 633680 (project DiscardLess). The authors are grateful 480 to the "Système d'Information Halieutique" (SIH), the "Marine Fisheries and Aquaculture 481 Administration"(DPMA) and all the persons involved in collecting and compiling survey 482 (CGFS) and on-board data (OBSMER program). The authors would also like to acknowledge 483 the Pôle Métropolitain de la Côte d'Opale for their financial supports. Finally we wish to thank 484 the anonymous referee and editor for helping us improve the manuscript. 
486

487 Abernethy, K.E., Allison, E.H., Molloy, P.P., and Côté, I.M. 2007. Why fishers fish where they

488 fish? Using the ideal free distribution to understand the behaviour of artisanal reef fishers. Can.

489 J. Fish. Aquat. Sci. 64: 1595-1604.

490 Abrahams, M.V., and Healey, M.C. 1993. Some consequences of variation in vessel density: a 491 manipulative experiment. Fish. Res. 15: 315-322.

492 Andersen, B.S., Vermard, Y., Ulrich, C., Hutton, T., Poos, J.J. 2010. Challenges in integrating 493 short-term behaviour in a mixed-fishery Management Strategies Evaluation frame: A case study 494 of the North Sea flatfish fishery. Fish. Res. 102: 26-40.

495 Bastardie, F., Nielsen, J.R., Ulrich, C., Egekvist, J. and Degel, H. 2010. Detailed mapping of 496 fishing effort and landings by coupling fishing logbooks with satellite-recorded vessel geo497 location. Fish. Res. 106: 41-53. doi:10.1016/j.fishres.2010.06.016

498 Batsleer, J., Poos, J.J., Marchal, P., Vermard, Y., and Rijnsdorp, A.D. 2013. Mixed fisheries 499 management: protecting the weakest link. Mar. Ecol. Prog. Ser. 479: 177-190.

500 Baudron, A.R., and Fernandes, P.G. 2015. Adverse consequences of stock recovery: European 501 hake, a new "choke" species under a discard ban? Fish. Fish. 16: 563-575.

502 Boonstra, W.J. and Hentati-Sundberg, J. 2014. Classifying fishers' behaviour. An invitation to 503 fishing styles. Fish. Fish. 17: 78-100. doi:10.1111/faf.12092

504 Bordalo-Machado, P. 2006. Fishing Effort Analysis and Its Potential to Evaluate Stock Size. 505 Rev. Fish. Sci. 14: 369-393.

506 Boucaud-Camou, E., and Boismery, J. 1991. The migrations of the cuttlefish (Sepia officinalis 507 L.) in the English Channel. In Boucaud-Camou, E., editor, La Seiche / The Cuttlefish, p. 179508 189, Caen, France. Centre de publication de l'Université de Caen. 
509 Bourdaud, P., Travers-Trolet, M., Vermard, Y., Cormon, X., and Marchal, P. 2017. Inferring the 510 annual, seasonal and spatial distributions of marine species from complementary research and 511 commercial vessel's catch rates. ICES J. Mar. Sci. In press.

512 Branch, T.A., Hilborn, R. and Bogazzi, E. 2005. Escaping the tyranny of the grid: a more 513 realistic way of defining fishing opportunities. Can. J. Fish. Aquat. Sci. 62: 631-642.

514 doi:10.1139/f04-232

515 Cardoso, I., Moura, T., Mendes, H., Silva, C., and Azevedo, M. 2015. An ecosystem approach to 516 mixed fisheries: technical and biological interactions in the Portuguese multi-gear fleet. ICES J. 517 Mar. Sci. 72: 2618-2626.

518 Carpentier A., Martin, C.S., and Vaz, S. (Eds.). 2009. Channel Habitat Atlas for marine 519 Resource Management, final report / Atlas des habitats des ressources marines de la Manche 520 orientale, rapport final (CHARMphase II). INTERREG 3a Programme, IFREMER, Boulogne521 sur-Mer, France. 626 pp. \& CD-rom.

522 Catchpole, T. L., Frid, C. L. J., and Gray, T. S. 2005. Discards in the North Sea fisheries: causes, 523 consequences and solutions. Marine Policy 29: 421-430.

524 Christensen, A.-S. and Raakjær, J. 2006. Fishermen's tactical and strategic decisions. Fish. Res. 525 81: 258-267. doi:10.1016/j.fishres.2006.06.018

526 Dauvin, J.-C. 2012. Are the eastern and western basins of the English Channel two separate 527 ecosystems? Mar. Pollut. Bull. 64: 463-471.

528 Dowling, N.A., Wilcox, C., Mangel, M., and Pascoe, S. Assessing opportunity and relocation 529 costs of marine protected areas using a behavioural model of longline fleet. Fish. Fish. 13: 139530157.

531 Eigaard, O.R., Marchal, P., Gislason, H., and Rijnsdorp, A.D. 2014. Technological

532 Development and Fisheries Management. Rev. Fish. Sci. Aquac. 22(2): 156-174. 
533 Eltink, A., Warmerdam, M., and Heinen, A. 1986. Origin, migration and spawning of southern 534 North Sea mackerel with respect to the overspill of Western mackerel to the North Sea stock. 535 ICES C.M. 1986/H:49, 15 pp.

536 European Commission. 1998. Official Journal of the European Communities, L125/1, 27.4.98, $537 \quad 19-20$.

538 FAO. 2001. Report of the Reykjavik Conference on Responsible Fisheries in the Marine 539 Ecosystem. Reykjavik, Iceland, 1-4 October 2001. FAO Fisheries Report No. 658. Rome/Roma, $540 \quad$ FAO. 2002. 128p.

541 Fernandes, P.G. and Cook, R.M. 2013. Reversal of fish stock decline in the North East Atlantic. 542 Curr. Biol. 23: 1-6.

543 Fretwell, S.D. 1972. Populations in a seasonal environment. Princeton University Press, 544 Princeton, N.J.

545 Fretwell, S.D., and Lucas, H.L. 1970. On territorial behavior and other factors influencing 546 habitat distributions in birds. Acta Biotheor. 19: 16-36.

547 Fulton, E.A., Smith, A.D.M., Smith, D.C., and van Putten, I.E. 2011. Human behaviour: the key 548 source of uncertainty in fisheries management, Fish. Fish. 12: 2-17.

549 García-Carreras, B., Dolder, P., Engelhard, G.H., Lynam, C.P., Bayliss-Brown, G.A., and 550 Mackinson, S. 2015. Recent experience with effort management in Europe: Implications for 551 mixed fisheries. Fish. Res. 169: 52-59.

552 Gascuel, D., Fonteneau, A. and Foucher, E. 1993. Analyse de l'évolution des puissances de 553 pêche par l'analyse des cohortes: application aux senneurs exploitant l'albacore (Thunnus 554 albacares) dans 1'Atlantique Est. Aquat. Living Resour. 6: 15-30.

555 Gillis, D.M. 2003. Ideal free distributions in fleet dynamics: a behavioural perspective on vessel 556 movement in fisheries analysis. Can. J. Zool. 81: 177-187. 
557 Gillis, D. and Frank., K.T. 2001. Influence of environment and fleet dynamics on catch rates of 558 eastern Scotian Shelf cod through the early 1980s. ICES J. Mar. Sci. 58: 61-69.

559 doi:10.1006/jmsc. 2000.0990

560 Gillis, D.M. and van der Lee, A. 2012. Advancing the application of the ideal free distribution to 561 spatial models of fishing effort: the isodar approach. Can. J. Fish. Aquat. Sci. 69: 1610-1620. 562 doi:10.1139/f2012-091

563 Gillis, D.M., Peterman, R.M., and Tyler, A.V. 1993. Movement dynamics in a fishery: 564 application of the ideal free distribution to spatial allocation of effort. Can. J. Fish. Aquat. Sci. 565 50: 323-333.

566 Giraldo C., Ernande B., Cresson P., Kopp D., Cachera M., Travers-Trolet M., and Lefebvre S. 567 2017. Depth gradient on the resource use of a fish community from a semi-enclosed sea. 568 Limnol. Oceanogr. In press. Publisher's official version : http://doi.org/10.1002//no.10561 569 Girardin, R., Vermard, Y., Thébaud, O., Tidd, A. and Marchal, P. 2015. Predicting fisher 570 response to competition for space and resources in a mixed demersal fishery. Ocean Coast. 571 Manag. 106: 124-135. doi:10.1016/j.ocecoaman.2015.01.017

572 Girardin, R., Hamon, K.G., Pinnegar, J., Poos, J.J., Thébaud, O., Tidd, A., Vermard, Y., and 573 Marchal, P. 2017. Thirty years of fleet dynamics modelling using discrete-choice models: What 574 have we learned? Fish. Fish. In Press. DOI: 10.1111/faf.12194.

575 Gordon, H.S. 1953. An economic approach to the optimum utilization of fishery resources. J. 576 Fish. Res. Board Can. 10: 442-457.

577 Gras, M., Roel, B.A., Coppin, F., Foucher, E., and Robin, J.-P. 2014. A two-stage biomass 578 model to assess the English Channel cuttlefish (Sepia officinalis L.) stock. ICES J. Mar. Sci. 579 71(9) : 2457-2468. doi:10.1093/icesjms/fsu081

580 Hilborn, R. 1985. Fleet dynamics and individual variation: why some people catch more fish 
581 than others. Can. J. Fish. Aquat. Sci. 42: 2-13.

582 Hind, E.J. 2015. A review of the past, the present, and the future of fishers' knowledge research:

583 a challenge to established fisheries science. ICES J. Mar. Sci. 72: 341-358.

584 doi:10.1093/icesjms/fsu169

585 Hintzen, N.T., Bastardie, F., Beare, D., Piet, G.J., Ulrich, C., Deporte, N., Egekvist, J., and

586 Degel, H. 2012. VMStools: Open-source software for the processing, analysis and visualisation 587 of fisheries logbook and VMS data. Fish. Res. 115-116: 31-43.

588 Holland, D.S., 2008. Are fishermen rational? A fishing expedition. Mar. Resour. Econ. 23: 325589344.

590 Horwood, J., O’Brien, C.M., and Darby, C. 2006. North Sea cod recovery? ICES J. Mar. Sci. $591 \quad 63: 961-968$.

592 ICES. 2015. Report of the Herring Assessment Working Group for the Area South of $62^{\circ} \mathrm{N}$ 593 (HAWG), 10-19 March 2015, ICES HQ, Copenhagen, Denmark. ICES CM 2015/ACOM:06. $594850 \mathrm{pp}$.

595 ICES. 2017. Report of the Working Group on the Assessment of Demersal Stocks in the North 596 Sea and Skagerrak (WGNSSK), 26 April-5 May 2016, Hamburg, Germany. ICES CM 2016/ 597 ACOM:14. 19pp.

598 Johnsen, J.P., and Eliasen, S. 2011. Solving complex fisheries management problems: What the 599 EU can learn from the Nordic experiences of reduction of discards. Marine Policy 35, 130-139. 600 Kacelnik, A., Krebs, J.R., and Bernstein, C. 1992. The ideal free distribution and predator-prey 601 populations. Trends Ecol. 7: 50-55.

602 Kennedy, M., and Grey, R.D. 1993. Can ecological theory predict the distribution of foraging 603 animals? A critical analysis of experiments on the ideal free distribution. Oikos 68: 158-166.

604 Kirkley, J., Morrison, P.C.J., Cunningham, S., and Cantzano, J.. 2004. Embodied and 
605 disembodied technical change in fisheries: an analysis of the Sète trawl fishery, 1985-1999. 606 Environ. Resour. Econ. 29: 191-217.

607 Larsonneur, C., Bouysse, P., and Lauffret, J-P. 1982. The superficial sediments of the English 608 Channel and its Western Approaches. Sedimentology 29: 851-864.

609 Laurec, A., Biseau, A., and Charuau, A. 1991. Modelling technical interactions. ICES Marine $610 \quad$ Science Symposia 193: 225-236.

611 van der Lee, A., Gillis, D.M., Comeau, P. and Quinn, T. 2014. Comparative analysis of the 612 spatial distribution of fishing effort contrasting ecological isodars and discrete choice models.

613 Can. J. Fish. Aquat. Sci. 71: 141-150. doi:10.1139/cjfas-2012-0511

614 Long, R.D., Charles, A., and Stephenson, R.L. 2015. Key principles of marine ecosystem-based 615 management, Marine Policy 57: 53-60.

616 Mahé K., Destombes A., Coppin F., Koubbi P., Vaz S., Leroy D. and Carpentier A. 2005. Le 617 rouget barbet de roche Mullus surmuletus (L. 1758) en Manche orientale et mer du Nord, 186 $618 \mathrm{pp}$.

619 Mahévas, S., Sandon, Y., and Biseau, A. 2004. Quantification of annual variations in fishing 620 power due to vessel characteristics: an application to the bottom-trawlers of South-Brittany 621 targeting anglerfish (Lophius budegassa and Lophius piscatorius). ICES J. Mar. Sci. 61: 71-83. 622 doi:10.1016/j.icesjms.2003.09.002

623 Mahévas, S., Vermard, Y., Hutton, T., Iriondo, A., Jadaud, A., Maravelias, C.D., Punzon, A., 624 Sacchi, J., Tidd, A., Tsitsika, E., Marchal, P., Goascoz, N., Mortreux, S. and Roos, D. 2011. An 625 investigation of human vs. technology-induced variation in catchability for a selection of 626 European fishing fleets. ICES J. Mar. Sci. 68: 2252-2263. doi:10.1093/icesjms/fsr150 627 Marchal, P. 2008. A comparative analysis of métiers and catch profiles for some French 628 demersal and pelagic fleets. ICES J. Mar. Sci. 65: 674-686. 
629 Marchal, P., Ulrich, C. and Pastoors, M. 2002. Area-based management and fishing efficiency. 630 Aquat. Living Resour. 15: 73-85.

631 Marchal, P., Andersen, B., Caillart, B., Eigaard, Guyader, O., Hovgaard, H., Iriondo, A., Le Fur, 632 F., Sacchi, J., and Santurtun, M. 2007. Impact of technological creep on fishing effort and 633 fishing mortality, for a selection of European fleets. ICES J. Mar. Sci. 64: 192-209.

634 Marchal, P., Lallemand, P., and Stokes, K. 2009. The relative weight of traditions, economics, 635 and catch plans in New Zealand fleet dynamics. Can. J. Fish. Aquat. Sci. 66: 291-311.

636 Marchal, P., De Oliveira, J.A.A., Lorance, P., Baulier, L., and Pawlowski, L. 2013. What is the 637 added value of including fleet dynamics processes in fisheries models? Can. J. Fish. Aquat. Sci. $638 \quad 70: 992-1010$.

639 Marchal, P., Bartelings, H., Bastardie, F., Batsleer, J., Delaney, A., Girdardin, R., Gloaguen, P., 640 Hamon, K., Hoefnagel, E., Jouanneau, C., Mahévas, S., Nielsen, R., Piwowarczyk, J., Poos, J.J., 641 Schulze, T., Rivot, E., Simons, S., Tidd, A., Vermard, Y., and Woillez, M. 2014. Mechanisms of 642 Change in Human Behaviour. EU FP7 VECTORS project, Grant Agreement No.266445, 643 Deliverable No. D231 193 pp.

644 McCluskey, S.M. and Lewison, R.L. 2008. Quantifying fishing effort: a synthesis of current 645 methods and their applications. Fish. Fish. 9: 188-200.

646 Morris, D.W. 1988. Habitat-dependent population regulation and community structure. Evol. 647 Ecol. 2: 253-269.

648 Morris, D.W. 2003. Toward an ecological synthesis: a case for habitat selection. Oecologia 136: 649 1-13. doi:10.1007/s00442-003-1241-4

650 Neis, B., Schneider, D.C., Felt, L., Haedrich, R.L., Fischer, J. and Hutchings, J.A. 1999.

651 Fisheries assessment: what can be learned from interviewing resource users? Can. J. Fish. 652 Aquat. Sci. 56: 1949-1963. 
653 Nielsen, J.R., Thunberg, E., Holland, D.S., Schmidt, J.O., Fulton, E.A., Bastardie, F., Punt, A.E., 654 Allen, I., Bartelings, H., Bertignac, M., Bethke, E., Bossier, S., Buckworth, R., Carpenter, G., 655 Christensen, A., Christensen, V., Da-Rocha, J.M., Deng, R., Dichmont, C., Doering, R., 656 Esteban, A., Fernandes, J.A., Frost, H., Garcia, D., Gasche, L., Gascuel, D., Gourguet, S., 657 Groeneveld, R.A., Guillén, J., Guyader, O., Hamon, K.G., Hoff, A., Horbowy, J., Hutton, T., 658 Lehuta, S., Little, L.R., Lleonart, J., Macher, C., Mackinson, S., Mahevas, S., Marchal, P., Mato659 Amboage, R., Mapstone, B., Maynou, F., Merzéréaud, M., Palacz, A., Pascoe, S., Paulrud, A., 660 Plaganyi, E., Prellezo, R., van Putten, E.I., Quaas, M., Ravn-Jonsen, L., Sanchez, S., Simons, S., 661 Thébaud, O., Tomczak, M.T., Ulrich, C., van Dijk, D., Vermard, Y., Voss, R. and Waldo, S. 662 2017. Integrated ecological-economic fisheries models-Evaluation, review and challenges for 663 implementation. Fish. Fish. In press. doi:10.1111/faf.12232

664 van Oostenbrugge, H.J.A.E., Powell, J.P., Smit, J.P.G., Poos, J.-J., Kraak, S.B.M. and Buisman, 665 E.F.C. 2008. Linking catchability and fisher behaviour under effort management. Aquat. Living 666 Resour. 21: 265-273. doi:10.1051/alr:2008035

667 Pawson, M. G., Pickett, G. D., Leballeur, J. Brown, M., and Fritsch, M. 2007. Migrations, 668 fishery interactions, and management units of sea bass (Dicentrarchus labrax) in Northwest 669 Europe. ICES J. Mar. Sci. 64: 332-345.

670 Pet-Soede, C., Van Densen, W.L.T., Hiddink, J.G., Kuyl, S. and Machiels, M.A.M. 2001. Can 671 fishermen allocate their fishing effort in space and time on the basis of their catch rates? An 672 example from Spermonde Archipelago, SW Sulawesi, Indonesia. Fish. Manag. Ecol. 8: 15-36. 673 Pikitch, E.K., Santora, C., Babcock, E.A., Bakun, A., Bonfil, R., Conover, D.O., Dayton, P. et 674 al. 2004. Ecosystem-based fishery management. Science 305: 346-347. 
675 Poos, J.J., Bogaards, J. A., Quirijns, F. J., Gillis, D. M., and Rijnsdorp, A. D. 2010. Individual 676 quotas, fishing effort allocation, and over-quota discarding in mixed fisheries. ICES J. Mar. Sci. $677 \quad 67: 323-333$.

678 Poos, J.J., Turenhout, M.N.J., A. E. van Oostenbrugge, H. and Rijnsdorp, A.D. 2013. Adaptive 679 response of beam trawl fishers to rising fuel cost. ICES J. Mar. Sci. 70: 675-684.

680 doi:10.1093/icesjms/fss 196

681 van Putten, I.E., Kulmala, S., Thébaud, O., Dowling, N., Hamon, K.G., Hutton, T., and Pascoe, 682 S. 2012. Theories and behavioural drivers underlying fleet dynamics models 13, 216-235.

683 van Putten, I.E., Gorton, R.J., Fulton, E.A., and Thébaud, O. 2013. The role of behavioural 684 flexibility in a whole of ecosystem model. ICES J. Mar. Sci. 70(1): 150-163.

685 Quirijns, F.J., Poos, J.J. and Rijnsdorp, A.D. 2008. Standardizing commercial CPUE data in 686 monitoring stock dynamics: Accounting for targeting behaviour in mixed fisheries. Fish. Res. 687 89: 1-8. doi:10.1016/j.fishres.2007.08.016

688 R Core Team. 2013. R: A language and environment for statistical computing. R Foundation for 689 Statistical Computing, Vienna, Austria. URL http://www.R-project.org/.

690 Ravard, D., Brind'Amour, A., and Trenkel, V. M. 2014. Evaluating the potential impact of 691 fishing on demersal species in the Bay of Biscay using simulations and survey data. Fish. Res. 692 157: 86-95.

693 Renard, D., Bez, N., Desassis, N., Beucher, H., and Ors, F. 2014. RGeostats: Geostatistical 694 Package. R Package version 10.0.8. MINES-ParisTech / ARMINES. Free download from: 695 http://cg.ensmp.fr/rgeostats.

696 Respondek, G., Groger, J., Floeter, J. and Temming, A. 2014. Variability of fishing effort for the 697 German brown shrimp (Crangon crangon) fishing fleet: influencing factors, and seasonal and 698 spatial patterns. ICES J. Mar. Sci. 71: 1805-1817. doi:10.1093/icesjms/fsu016 
699 Rijnsdorp, A.D., Dol, W., Hoyer, M., and Pastoors, M.A. 2000. Effects of fishing power and 700 competitive interactions on the effort allocation on the trip level of the Dutch beam trawl fleet. 701 ICES J. Mar. Sci. 57: 927-937.

702 Rijnsdorp, A., Daan, N. and Dekker, W. 2006. Partial fishing mortality per fishing trip: a useful 703 indicator of effective fishing effort in mixed demersal fisheries. ICES J. Mar. Sci. 63: 556-566. 704 doi:10.1016/j.icesjms.2005.10.003

705 Rose, G., and Kulka, D. 1999. Hyperaggregation of Fish. Fish.: how catch-per-unit-effort 706 increased as the northern cod (Gadus morhua) declined. Can. J. Fish. Aquat. Sci. 56: 118-127. 707 Sagarese, S.R., Frisk, M.G., Cerrato, R.M., Sosebee, K.A., Musick, J.A., and Rago, P.J. 2015. 708 Spatiotemporal overlap of spiny dogfish (Squalus acanthias) and commercial fisheries in the 709 northeast U.S. shelf large marine ecosystem. Fish. Bull. 113: 101-120.

710 Salas, S. and Gaertner, D. 2004. The behavioural dynamics of fishers: management implications. 711 Fish. Fish. 5: 153-167.

712 Salthaug, A., and Aanes, S. 2003. Catchability and the spatial distribution of fishing vessels. 713 Can. J. Fish. Aquat. Sci. 60: 259-268.

714 Schrope, M. 2010. What's the catch? Nature 465: 540-542.

715 Scrimgeour, G. J., and Winterbourn, M. J. 1987. Diet, food resource partitioning and feeding 716 periodicity of two riffle-dwelling fish species in a New Zealand river. J. Fish. Biol. 31: 309-324.

717 Smith, M.D. 2005. State dependence and heterogeneity in fishing location choice. J. Environ. 718 Econ. Manag. 50: 319-340. doi:10.1016/j.jeem.2005.04.001

719 Stelzenmüller, V., Maynou, F., Bernard, G., Cadiou, G., Camilleri, M., Crec'hriou, R., Criquet, 720 G., Dimech, M., Esparza, O., Higgins, R., Lenfant, P., and Pérez-Ruzafa. 2008. Spatial 721 assessment of fishing effort around European marine reserves: Implications for successful 722 fisheries management. Mar. Pollut. Bull. 56: 2018-2026. 
723 Thorson, J.T. and Ward, E.J. 2014. Accounting for vessel effects when standardizing catch rates

724 from cooperative surveys. Fish. Res. 155: 168-176. doi:10.1016/j.fishres.2014.02.036

725 Tidd, A.N. 2013. Effective fishing effort indicators and their application to spatial management 726 of mixed demersal fisheries. Fish. Manag. Ecol. 20: 377-389. doi:10.1111/fme.12021

727 Tidd, A., Vermard, Y., Pinnegar, J., Marchal, P., Blanchard, J., and Milner-Gulland, E.J. 2015.

728 Fishing for space: fine-scale multi-sector maritime activities influence fisher location choice.

729 PLOS One 10, e0116335.

730 Ulrich, C., Le Gallic, B., Dunn, M.R., and Gascuel, D. 2002. A multi-species multi-fleet 731 bioeconomic simulation model for the English Channel artisanal fisheries. Fish. Res. 58: 379732401.

733 Ulrich, C., Reeves, S.A., Vermard, Y., Holmes, S.J. and Vanhee, W. 2011. Reconciling single734 species TACs in the North Sea demersal fisheries using the Fcube mixed-fisheries advice 735 framework. ICES J. Mar. Sci. 68: 1535-1547.

736 Ulrich, C., Wilson, D.C.K., Nielsen, J.R., Bastardie, F., Reeves, S.A., Andersen, B.S., and 737 Eigaard, O.R. 2012. Challenges and opportunities for fleet- and métier-based approaches for 738 fisheries management under the European Common Fisheries Policy, Ocean Coast. Manag. 70: $739 \quad 38-47$.

740 Vermard, Y., Marchal, P., Mahévas, S., and Thébaud, O. 2008. A dynamic model of the Bay of 741 Biscay pelagic fleet simulating fishing trip choice: the response to the closure of the European 742 anchovy (Engraulis encrasicolus) fishery in 2005. Can. J. Fish. Aquat. Sci. 65(11): 2444-2453.

743 Wilen, J.E., Smith, M.D., Lockwood, D., and Botsford, F.W. 2002. Avoiding surprises:

744 incorporating fisherman behaviour into management models. Bull. Mar. Sci. 70: 553-575.

745 Wilson, D. C., and Jacobsen, R. B. 2009. Governance Issues in Mixed-Fisheries Management:

746 An Analysis of Stakeholder Views. IFM - Innovative Fisheries Management. 
747 Winker, H., Kerwath, S.E., and Attwood, C.G. 2013. Comparison of two approaches to 748 standardize catch-per-unit-effort for targeting behaviour in a multispecies hand-line fishery. 749 Fish. Res. 139: 118-131.

750 Woillez, M., Rivoirard, J., and Petitgas, P. 2009. Notes on survey-based spatial indicators for 751 monitoring fish populations. Aquat. Living Resour. 22: 155-164. 


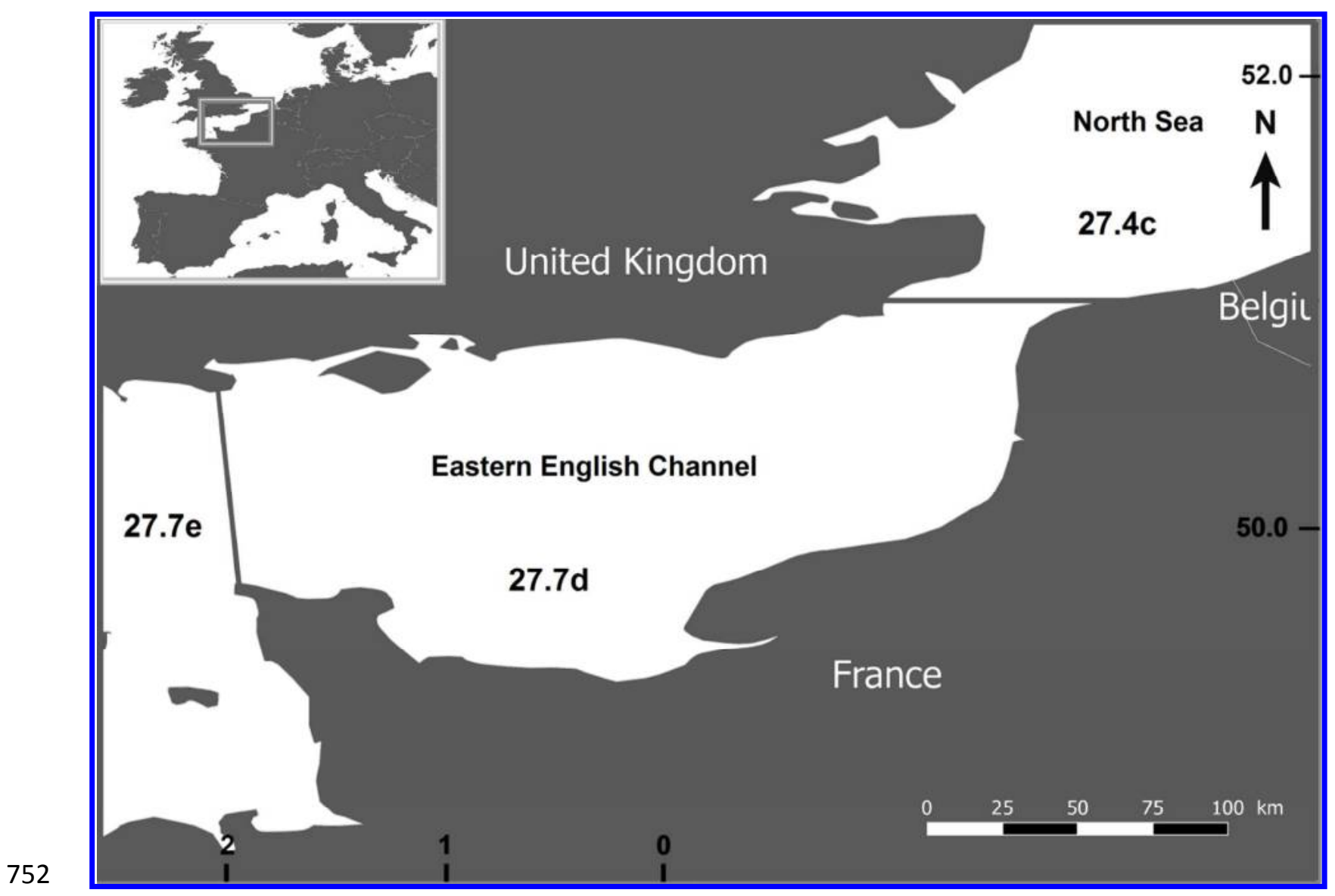

753 Figure 1. Study area of the Eastern English Channel, corresponding to the ICES Division 27.7d. 754 


\section{5}
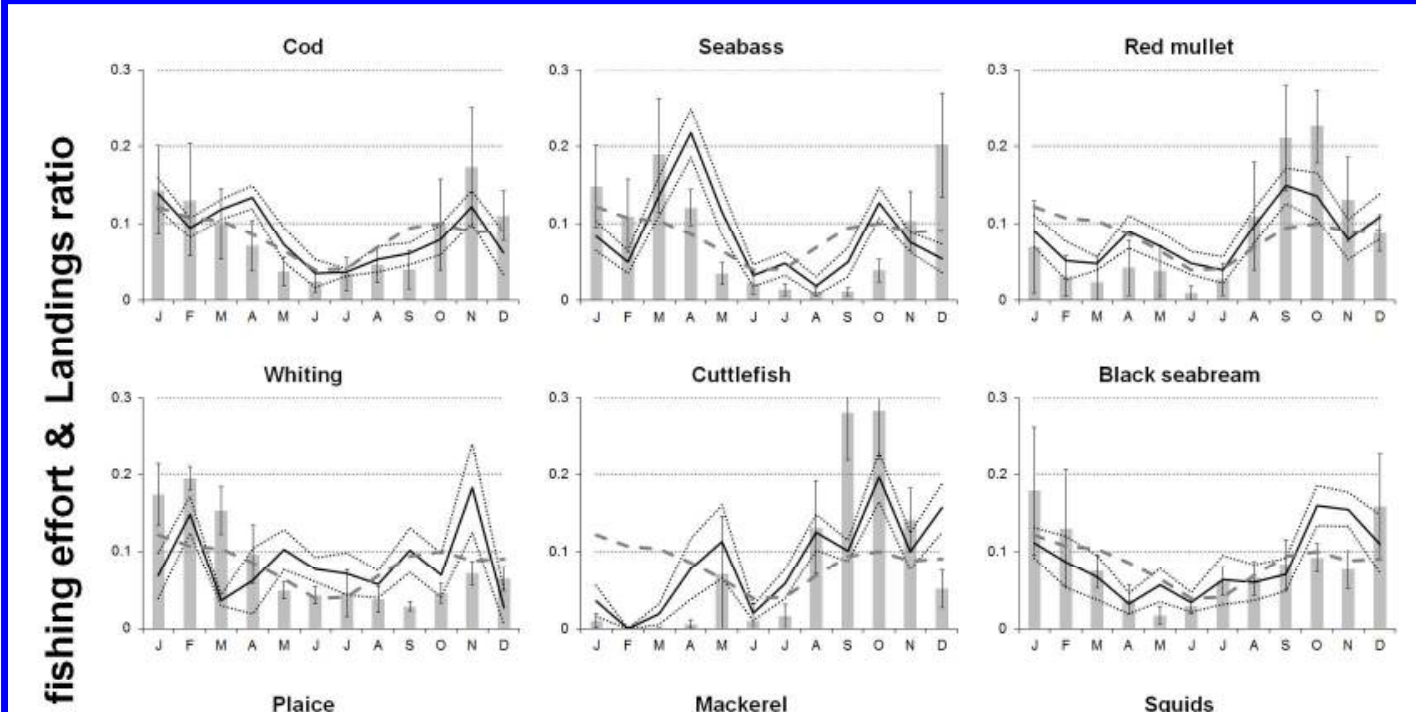

Landings
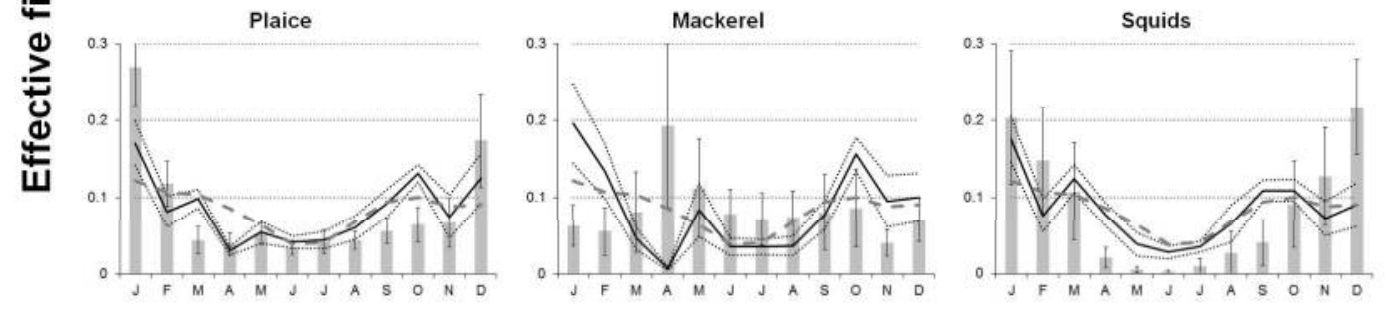

Effective

fishing

effort

Nominal

fishing

effort

756 Figure 2. Average monthly nominal fishing effort, effective fishing effort and yearly

757 standardized landings of exclusive bottom otter trawlers for nine main commercial species of the

758 Eastern English Channel. Dotted lines and error bars indicate inter-annual variability over the 759 period 2008-2014. 


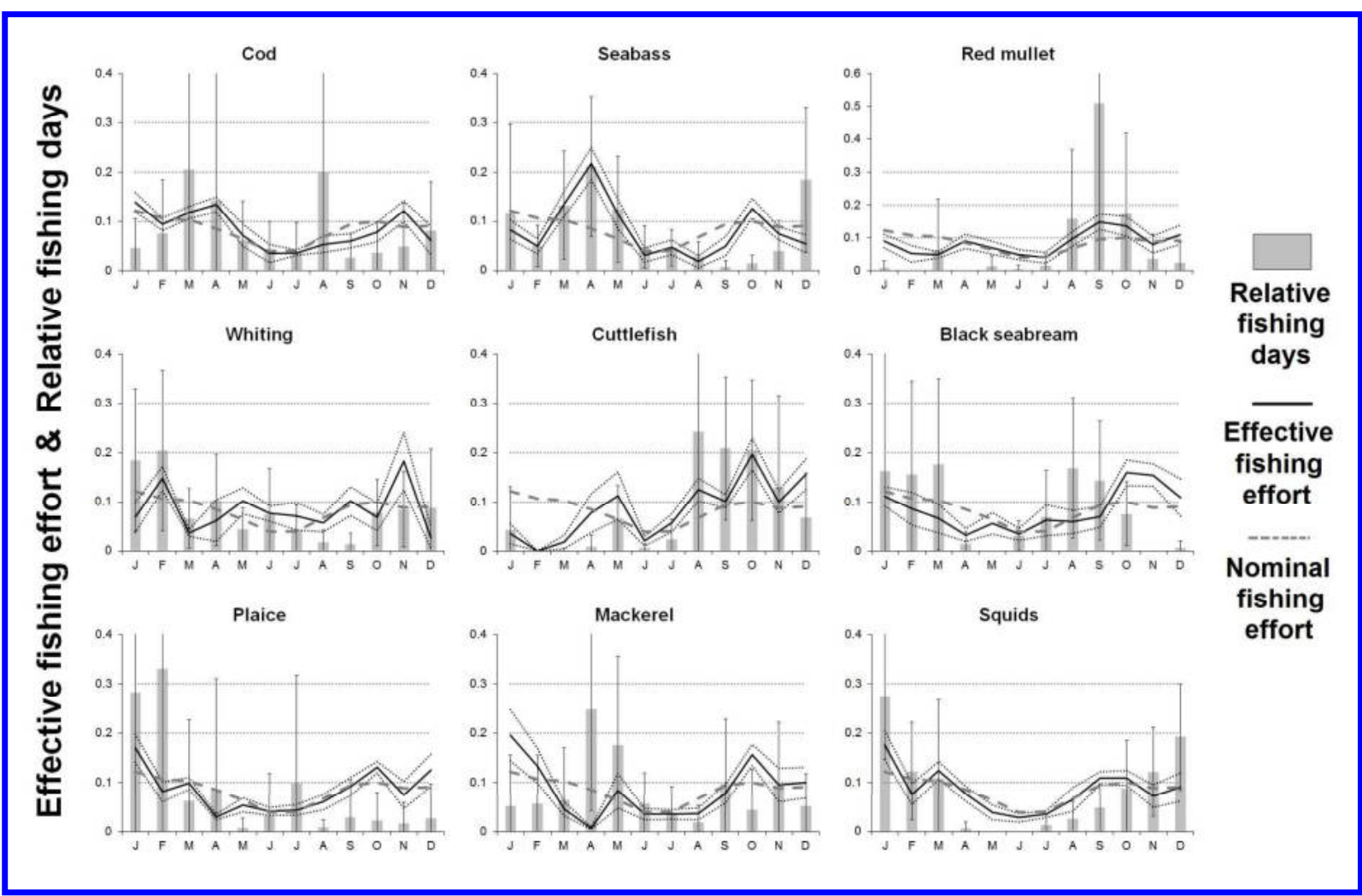

762 Figure 3. Average monthly nominal fishing effort, effective fishing effort and yearly

763 standardized number of fishing days from activity calendars of exclusive bottom otter trawlers

764 for nine main commercial species of the Eastern English Channel. Dotted lines and error bars 765 indicate inter-annual variability over the period 2008-2014. 


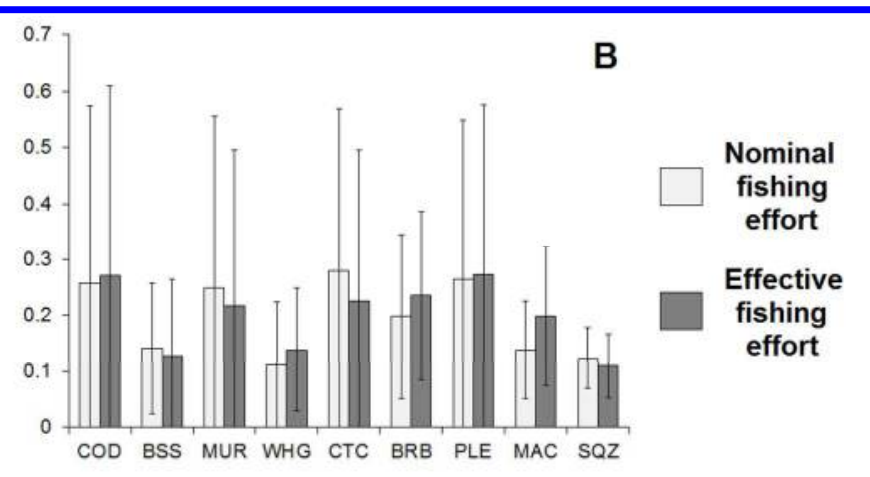

769 Figure 4. RSSQ between the monthly-resolved time series of (A) (i) nominal fishing effort and

770 landings, (ii) effective fishing effort and landings; (B) (iii) nominal fishing effort and fishers'

771 intention, (iv) effective fishing effort and fishers' intention; for nine key commercial species

772 caught by exclusive bottom otter trawlers operating in the Eastern English Channel. Error bars

773 indicate inter-annual variability over the period 2008-2014. COD: cod. BSS: Seabass. MUR: red

774 mullet. WHG: whiting. CTC: cuttlefish. BRB: black seabream. PLE: plaice. MAC: mackerel.

775 SQZ: squids.

776 


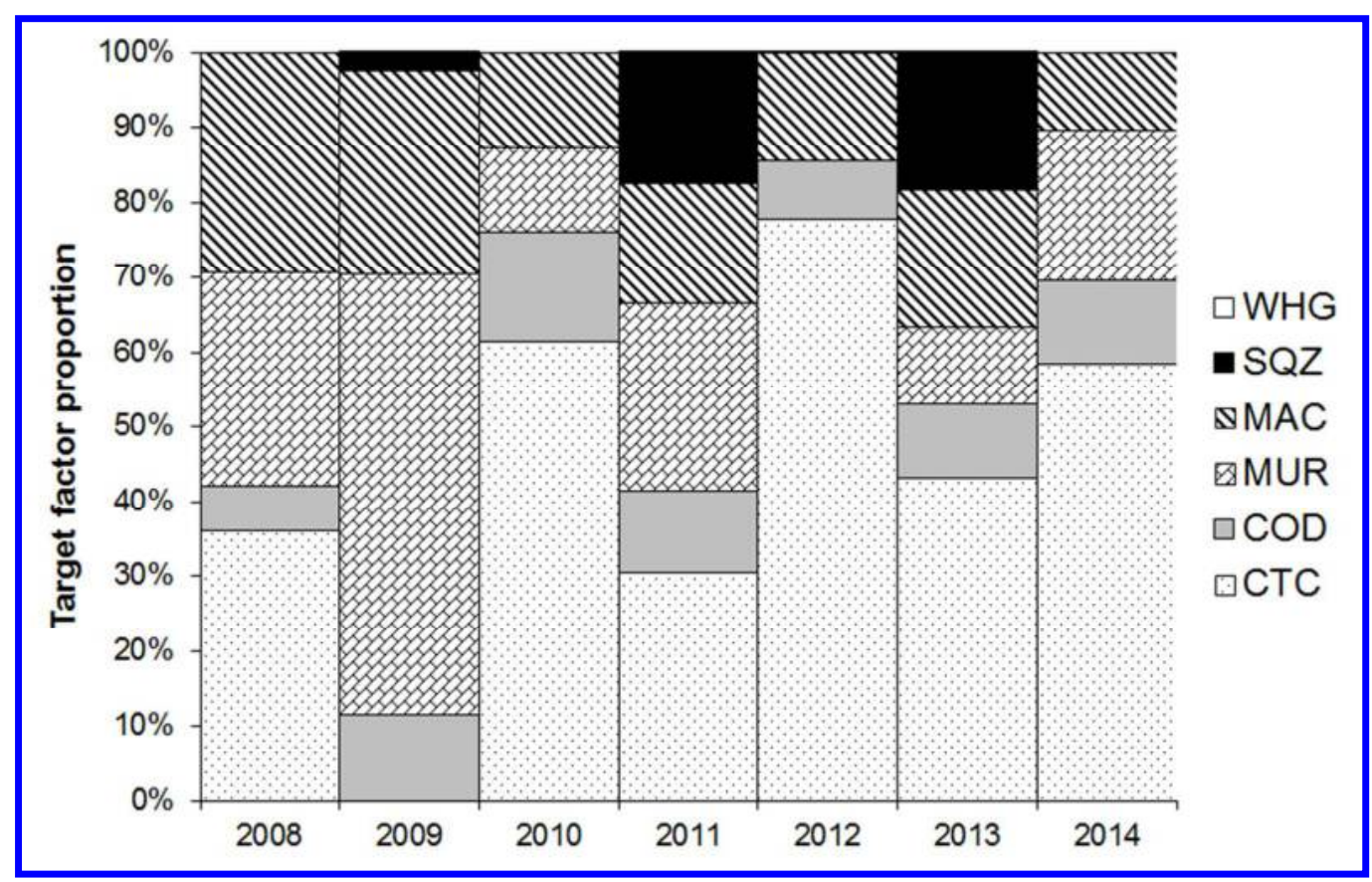

778 Figure 5. Relative target factor in October for whiting (WHG), squids (SQZ), mackerel (MAC), 779 red mullet (MUR), cod (COD) and cuttlefish (CTC) for exclusive bottom otter trawlers in 780 October over the period 2008-2014 in the Eastern English Channel, estimated by maximizing 781 the Local Index of Collocation. 

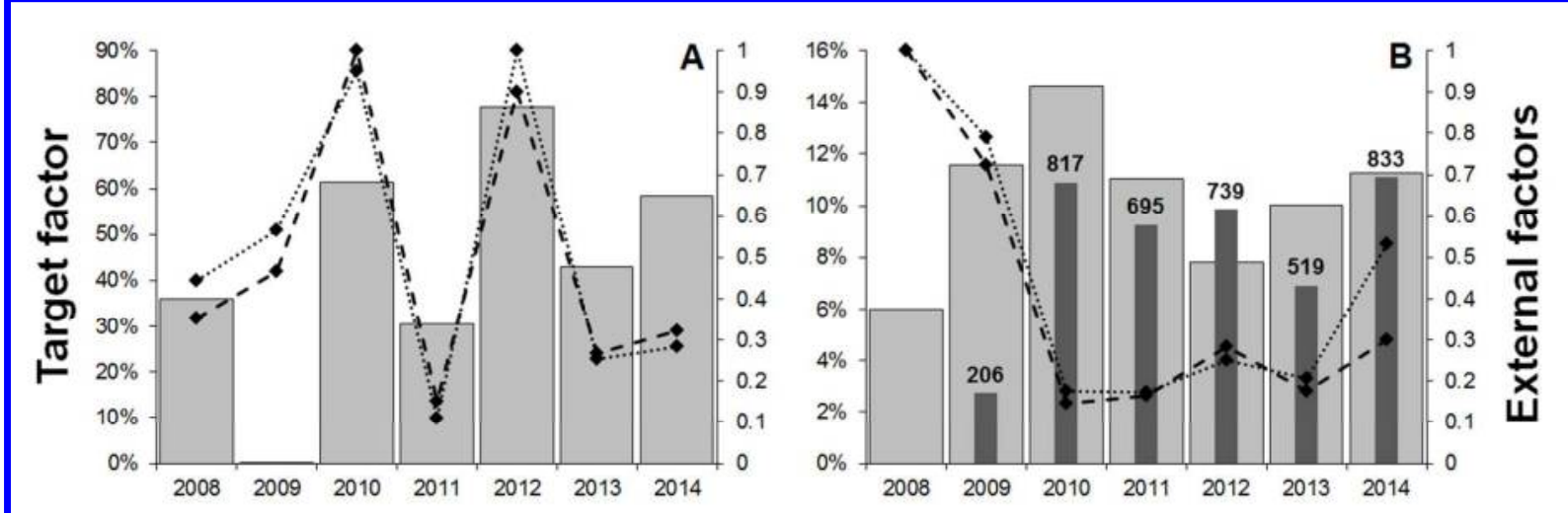

784 Figure 6. Relative A) cuttlefish and B) cod targeting factors in October, over the period 2008-

7852014 (light grey bars), compared to their relative abundances (dotted lines), relative economic 786 attractiveness's (abundance x price; dashed lines) and remaining French quota in tons for cod 787 (dark grey bars). 
789 Table 1. List of Eastern English Channel species considered in this study, with their Minimum 790 Landing Size (MLS, in $\mathrm{cm}$ ) when existing, the minimum total length $\mathrm{L}_{\mathrm{s}}(\mathrm{cm})$ above which 791 individuals are considered to be equally selected by survey and commercial gears, and their 792 closest code in commercial activity calendars.

\begin{tabular}{|c|c|c|c|c|}
\hline Common name & Scientific name & $\begin{array}{r}\text { MLS } \\
(\mathrm{cm}) \\
\end{array}$ & $\begin{array}{c}\mathbf{L}_{\mathbf{s}} \\
(\mathrm{cm})\end{array}$ & $\begin{array}{c}\text { Activity calendars } \\
\text { code } \\
\end{array}$ \\
\hline European seabass & Dicentrarchus labrax & 36 & 36 & Bass (miscellaneous) \\
\hline Atlantic cod & Gadus morhua & 35 & 35 & Cod \\
\hline Squids & Loligo spp. & - & $14^{*}$ & $\begin{array}{c}\text { Squids } \\
\text { (miscellaneous) }\end{array}$ \\
\hline Whiting & $\begin{array}{c}\text { Merlangius } \\
\text { merlangus }\end{array}$ & 27 & 27 & Whiting \\
\hline Red mullet & Mullus surmuletus & - & 15 & $\begin{array}{c}\text { Red mullet } \\
\text { (miscellaneous) }\end{array}$ \\
\hline European plaice & Pleuronectes platessa & 27 & 27 & $\begin{array}{c}\text { Flatfishes } \\
\text { (miscellaneous) }\end{array}$ \\
\hline Atlantic mackerel & Scomber scombrus & 20 & 20 & $\begin{array}{c}\text { Mackerel } \\
\text { (miscellaneous) }\end{array}$ \\
\hline Common cuttlefish & Sepia officinalis & - & $13 *$ & $\begin{array}{l}\text { Cuttlefish, sepia } \\
\text { (miscellaneous) }\end{array}$ \\
\hline Black seabream & $\begin{array}{c}\text { Spondyliosoma } \\
\text { cantharus }\end{array}$ & - & 17 & $\begin{array}{c}\text { Sparidae (seabream, } \\
\text { dentex, sargo, ...) }\end{array}$ \\
\hline
\end{tabular}


795 Table 2. Overlapping LIC values between the distribution of fishing effort and the distribution 796 of potential revenue (revenue-based LIC) or the combined distributions of species (maximized 797 LIC). The difference between both metrics measures the deviation between actual fishing effort 798 distribution and that predicted by IFD.

\begin{tabular}{cccc}
\hline & $\begin{array}{c}\text { Revenue- } \\
\text { based LIC }\end{array}$ & Maximized LIC & Difference \\
\hline 2008 & 0.63 & 0.81 & +0.18 \\
\hline 2009 & 0.59 & 0.74 & +0.15 \\
\hline 2010 & 0.46 & 0.64 & +0.18 \\
\hline 2011 & 0.57 & 0.70 & +0.13 \\
\hline 2012 & 0.52 & 0.74 & +0.22 \\
\hline 2013 & 0.46 & 0.57 & +0.11 \\
\hline 2014 & 0.51 & 0.73 & +0.22 \\
\hline
\end{tabular}

